\title{
Symptoms of subordinated importance in fibromyalgia when differentiating working from non-working women
}

\author{
Gunilla Liedberg and Mathilda Björk
}

\section{Linköping University Post Print}

\section{Tweet}

N.B.: When citing this work, cite the original article.

Original Publication:

Gunilla Liedberg and Mathilda Björk, Symptoms of subordinated importance in fibromyalgia when differentiating working from non-working women, 2014, Work: A journal of Prevention, Assesment and rehabilitation, (48), 2, 155-164.

http://dx.doi.org/10.3233/WOR-131607

Copyright: IOS Press http://www.iospress.nl/

Postprint available at: Linköping University Electronic Press http://urn.kb.se/resolve?urn=urn:nbn:se:liu:diva-97499 
Title: Symptoms of subordinated importance in fibromyalgia when differentiating working from non-working women

Liedberg GM. PhD, MSc OT, Senior Lecturer, Department of Social and Welfare Studies, Faculty of Health Sciences, Linköping University, Linköping, Sweden

Björk M. PhD, BSc OT, Senior Lecturer, Department of Rehabilitation, School of Health Sciences, Jönköping University, Jönköping, Sweden.

Corresponding author: Gunilla Liedberg

Department of Social and Welfare Studies Occupational Therapy Programme 60174 Norrköping, Sweden Phone: $+46(0) 11363251$

Email: gunilla.liedberg@liu.se

Key words: biopsychosocial model, comorbidity, daily activities, employment

Short title: Differentiating between working and non-working women with fibromyalgia 


\section{Abstract}

Background: The aim was to identify differences in self-reported symptoms among working (W) and non-working (NW) women, and to determine the most important biopsychosocial variables in differentiating one group from the other.

Method: A questionnaire was mailed to 524 members of a local chapter of the Swedish Rheumatology Association. A total of 362 persons responded (69\%); 96\% of which were women. Women older than 64 years and all men were excluded. The final study group consisted of $95 \mathrm{~W}$, and $227 \mathrm{NW}$ women. The questionnaire included data on demographics, employment, support, exercise, daily activities and symptoms. Data were analysed using univariate statistics and a partial least squares discriminant analysis (PLSDA).

Results: The results showed that $41 \%$ of the W and $42 \%$ of the NW women were/had been employed in service, care or business. The NW women reported a significantly higher severity of symptoms compared with the $\mathrm{W}$ women. The most important variable when differentiating the $\mathrm{W}$ from the $\mathrm{NW}$ women was social support from colleagues and employers.

Conclusion: To change prevailing attitudes and values towards persons with a work disability, a process of active intervention involving staff is needed. Educating employers as to how a disability may influence a work situation, and the importance of social support, can be improved. 


\section{BACKGROUND}

The aim of this study was to identify differences in self-reported symptoms among working (W) and non-working women (NW) with fibromyalgia (FM), and to determine the most important biopsychosocial variables in differentiating one group from the other. Fibromyalgia (FM) is characterised by persistent, widespread muscle pain with generalised hyperalgesia and allodynia [1]. FM is prevalent in about $2 \%$ of the general global population $[1,2]$, and is six times more common in women than in men [1]. A FM condition usually becomes permanent $[3,4]$, affecting quality of life and employability $[5,6]$. Pain location can vary daily and even during the day. Pain-free periods are uncommon, with as few as a third of patients reporting pain-free intervals [7]. The major symptoms of FM (pain, tiredness, disrupted sleep and muscle weakness) have been shown to severely impact everyday activities [8-10], including the ability to remain in a work role [11-13].

Work ability in persons with FM is affected by pain, fatigue, weakness and memory and concentration difficulties [14]. In addition to the previously mentioned symptoms, a Swedish study investigating employed women with FM [12] reported limiting symptoms such as decreased mobility and endurance, and slowness. White et al [14] found other factors predicting work ability in persons with FM, namely levels of satisfaction with 
health, the number of tender points, education level and the number of major symptoms. Lower education level and heavy work influenced the level of flexibility in work [15], and older age had a negative influence on the likelihood of returning to work [14]. Additionally, a pilot study showed a rapid decrease in the percentage of young women with FM working in paid employment. The employed subgroup was older (mean age 34) and perceived physical activities of daily living considerably less difficult [11]. Individual perceptions of facilitating or hindering factors for remaining at work showed that disability depends not only on a person's limitations, but also on the inability of society to adapt work environments and tasks to an individual's capacity [13].

A well-performed assessment of disability should be based on a biopsychosocial model $[16,17]$. The term 'disability' has a complex meaning and is described in the International Classification of Functioning, Disability and Health (ICF) [18] as capturing not only the consequences of the disease but also the context of an individual's life. Therefore, disability needs to be addressed at different levels, including personal and environmental factors. The aim of this study is to identify differences in self-reported symptoms among working (W) and non-working (NW) women, and to determine the most important biopsychosocial variables in differentiating one group from the other. The hypothesis is that other factors besides the FM condition could have a major impact on work ability. The specific research questions are: to examine differences in the type of work, to examine symptom severity, and to examine factors discriminating between working and non-working women. 


\section{METHOD}

\subsection{Procedures}

This study was done as part of a larger project entitled Health Care Interventions -

Patient Perspective, which was conducted in collaboration with a fibromyalgia chapter of a regional branch of the Swedish Rheumatism Association. The Swedish Rheumatism Association is an organisation with voluntary membership and has no connection with health care. It includes a number of chapters, one of which is fibromyalgia. Participant inclusion criteria were: a reported diagnosis of fibromyalgia, and membership of the FM chapter of the Swedish Rheumatism Association in the South Eastern region of Sweden. A questionnaire, including an informed consent to sign and return, was mailed to all 524 members of the specified FM chapter. If a questionnaire had not been returned to the research unit after four weeks, a reminder was posted. A further reminder was sent if the questionnaire had not been returned after seven weeks. The project was approved by Linköping University’s Research Ethics Committee, Sweden.

\subsection{Participants}

Of the total questionnaires sent out, 362 persons responded to the survey (69\%), of which $347(96 \%)$ were women. They all reported having a FM diagnosis and were members of the specified FM chapter. All men, and women older than 64 years were excluded since the retirement age in Sweden is 65. The final study group consisted of 95 working women with FM (full-time, part-time or studying full-time), and 227 women who were not working at all because of FM. Further demographic data concerning the participants are presented in table 1. 


\subsection{Instruments}

The questionnaire was designed to cover the different aspects of the biopsychosocial model [19] and included both demographic questions commonly used in previous research [10-12], and instruments measuring daily activities and symptoms. To collect demographic data, questions concerning age, family status, marital status, number of children living at home, education, level of exercise, work status (working full-time/part time or not working), type of work and time since diagnosis were included. The participants were also asked how often they had contacted a physician regarding issues with FM during the last year. Pain-specific information was also elicited such as: muscle pain duration, pain characteristics such as frequency of pain and pain-free periods, least and worst pain as measured by a visual analogue scale (VAS). The experienced social support from relatives and friends in the time since diagnosis were marked on four different VAS scales with end points 'totally agree' to 'not agree at all'. Similar VAS scales were used in measuring the experienced social support, present, or past if not working, from colleagues and employers in the time since diagnosis.

Further, the impact of the symptoms on daily activities was measured by using the Fibromyalgia Impact Questionnaire (FIQ) physical functioning subscale [20]. The subscale consists of the following items: do shopping, do laundry with a washer and dryer, prepare meals, wash dishes/cooking utensils by hand, vacuum a rug, make beds, walk several blocks, visit friends or relatives, do yard work, drive a car, climb stairs. The participants were asked to rate how well they had managed these activities during the last 
week on a 4-point scale, where 1 indicated 'all the time' and 4 indicated 'not at all'. The Swedish version of the questionnaire has been validated [21].

To measure physical and psychological symptoms, the Fibromyalgia Symptom Inventory (FSI) (Liedberg G., Gullberg M., Wood P. unpublished) was included in the questionnaire.

A preliminary analysis of the FSI resulted in good internal consistency and reliability of the instrument as a whole, supported by a Cronbach's alpha of 0.88 (Liedberg G., Gullberg M., Wood P. unpublished). The FSI instrument consists of 29 items: widespread pain or "hurting all over", fatigue or "tired all the time", stiffness, problems sleeping, numbness or tingling sensations, headaches, swelling in hands, arms, legs or feet, feeling tense, worried or "stressed out", feeling sad or "blue", problems with menstrual periods or "PMS", Pain or discomfort with sexual intercourse, low sex drive/decreased libido, problems with urination - pain, urgency or frequency, dry mouth, dry or scratchy eyes, irritable bowels: constipation, irritable bowels: diarrhoea, abdominal pain/cramps, restless legs or leg cramps, problems with concentration, problems with memory, difficulty with balance or dizziness, sinus pain, congestion or stuffiness, painful chewing or "TMJ", cold sensitivity in hands or feet, decreased muscle strength, decreased muscle endurance, leg cramps during night, and tenderness to touch. During the assessment these items were self-rated by patients on a six-point categorical scale (i.e. 'none', 'minimal', 'mild', 'moderate', 'severe' and 'unbearable'). Scoring the instrument involves the assignment of ascending numerical values to each category (none $=0$, unbearable $=5$ ), 
and then adding these to result in a maximum score of 145 for the 29 items. Finally, the participants rated their global satisfaction with life on a VAS with end points 'not at all satisfied' (indicated zero) to 'satisfied to a very high degree'.

\subsection{Data analysis}

For statistical purposes the participants were classified into a working (W) and a nonworking (NW) group. Those employed part- or full-time outside the home, or who were studying full-time, were counted as working. Statistical differences between W and NW women were determined using Student's t-tests and chi-squared tests. P-values $<0.05$ (2-tailed) were considered significant. In order to identify variables differentiating the W from the NW women, a multivariate projection method, Partial Least Squares by means of Projection to Latent Structures (PLS) [22, 23], was obtained using the software SIMCA P+. The three basic analytical questions to which projection methods such as PLS can be applied are (a) an overview of data, (b) classification and/or discrimination among groups of observations, and (c) regression modelling between two blocks of data (X and $\mathrm{Y}$ ). In the latter, data are reduced to a few latent variables, principal components (PC), which summarise the original variables and express the relationship between $\mathrm{X}$ and Y.

In the present study, an extension of PLS, partial least squares discriminant analysis (PLS-DA), was used [22]. The aim of the PLS-DA was to discriminate the working and the non-working women from each other and to identify the most important variables for the discrimination. In the PLS-DA, the X-variables (independent variables) consisted of 
physical and psychological symptoms (FSI), demographic data (age, education marital status, children living at home, work status), duration of muscle pain, time since diagnosis, number of contacts with a physician regarding their FM, pain characteristics (occurrence of pain-free periods, worst and least pain intensity, exercise, support from relatives, friends, colleagues and employers, impact of pain in daily activities, FIQ and global life satisfaction. The Y-variable (the dependent variable) was a dummy-variable that described class membership, here identified as working (full-time or part-time) or non-working.

To interpret the total model, a value of how much variation the PCs explain $\left(\mathrm{R}^{2}\right)$ is given, together with a value of the predictive power of the model $\left(\mathrm{Q}^{2}\right)$. The $\mathrm{Q}^{2}$ value is calculated using a cross-validation technique by SIMCA-P+. The basic idea of the crossvalidation is to keep a portion of the data out of the model, develop a number of parallel models from the reduced data, and predict the omitted data by the different models. Finally, the predicted values are compared to the actual ones. PLS provides variablerelated parameters to facilitate the interpretation of the model. The variable influence on projection (VIP) identifies the most prominent variables for the model. X-variables with a VIP $\geq 1.0$ are considered as the most influential variables in the model [22], and here as the most important variables discriminating between the W and NW groups.

\section{RESULTS}

Differences between the working and non-working women are reported in table 1 . There were significant differences between the $\mathrm{W}$ and NW groups for age, family status and 
education; women with a nine-year school education were less likely to be working than those with a university education. The working women were more likely to be married and more often had children living at home. The working and non-working women also had different exercise habits, and the non-working women reported a significantly higher impact of pain on daily activities. There were no differences in muscle pain duration or number of visits to the physician during the last year, but the NW women had their diagnosis of fibromyalgia for significantly longer and reported a higher pain intensity and fewer pain-free periods than the $\mathrm{W}$ women. The $\mathrm{W}$ and NW women reported similar social support from family and relatives, but the $\mathrm{W}$ women reported better support from their employers and colleagues. On the question of satisfaction with global life situation, the $\mathrm{W}$ group was significantly more satisfied than the NW group.

Insert Table 1 here

The participants' type of work was coded according to the Swedish version of the International Classification of Occupation [24] (table 2). Forty-one percent of the W women and $42 \%$ of the NW women were/had been employed in service, care or business. Work without formal vocational training (e.g. cleaner, catering assistant) was done by $14 \%$ of the $\mathrm{W}$ and previously done by $15 \%$ of the NW group. Fifteen percent of the W women were employed in administration and customer service, and $11 \%$ of the women in the NW group had been employed in administration and customer service (table 2).

\section{Insert Table 2 here}

3.1 Symptom severity among working and non-working women 
The symptoms the NW group reported as significantly more severe than the W group included: widespread pain or "hurting all over", decreased muscle strength, decreased muscle endurance, stiffness, pain or discomfort with sexual intercourse, dry mouth, abdominal pain/cramps, restless legs or leg cramps, leg cramps at night, problems with concentration, and problems with memory. The symptoms with the highest mean value (severity) in the NW group were: decreased muscle endurance, tenderness to touch, and fatigue or "tired all the time". The symptoms with the lowest reported severity were problems with urination - pain, urgency or frequency, sinus pain, congestion or stuffiness, and problems with menstrual periods or "PMS" (table 3).

\section{Insert Table 3 here}

3.2 Variables discriminating working from non-working women

The PLS-DA model identified two significant PCs explaining $29 \%\left(\mathrm{R}^{2}\right)$ of the group difference (W or NW) $\left(\mathrm{Q}^{2} 15 \%\right)$. The most important discriminating variables were perceived support from colleagues, and support from the employer (table 4).

Rank ordering the importance of symptoms in discriminating whether the women were working or not resulted in headaches and widespread pain or "hurting all over" being indicated as most important. The symptoms of no significant value when discriminating between the working and the non-working women included problems sleeping, and decreased muscle strength. The model also identified activity limitations as important for the outcome of $\mathrm{W}$ or $\mathrm{NW}$, for example driving a car, climbing stairs or doing shopping. Variables such as age, level of education, children living at home, the least and worst 
pain intensity, time since diagnosis of FM, and exercising were also important for determining whether one remained in a work role or not (table 4).

\section{Insert Table 4 here}

The VIP values in table 4 can be interpreted as positive or negative associations. In conclusion, women in the $\mathrm{W}$ group had higher levels of support from colleagues and employers than did NW women, and could manage daily activities such as driving a car, doing yard work, and cleaning better than the NW group. However, they also rated their level of least pain higher on average than the NW women.

\section{DISCUSSION}

The major finding in this study is that social support from colleagues and employers is of highest importance when differentiating working women from non-working.

For the non-working women it was obvious they had experienced less support from their previous employer and colleagues when they were working. Earlier interview studies $[13,25]$ also demonstrated the importance of the psychosocial environment for fibromyalgia patients in both returning to, as well as remaining at, a work placement. Löfgren et al. [25] showed that the women participating in their study felt that it was common to have an understanding manager or supervisor, but described their work colleagues as not supportive. The importance of supportive workmates who understand the problems of women with FM was also emphasised in another study [13], and showed that the psychosocial environment influences whether women volunteer information about their problems in a work situation. Social support has frequently been reported as a 
significant factor affecting the likelihood of returning to work [26], but high levels of support may also enable individuals with disabilities to remain in the workforce. Still, more information is needed about the meaning of social support to particular individuals in specific work situations. House [27] describes two types of support: organisational and supervisory support. This framework might be useful in future studies designed to identify what kind of social support is most important in retaining individuals with disabilities in the workforce, and could shed light on how we should educate employers to better support their workers. The present study highlighted the importance of social support from employers and employees. Nevertheless, more information is needed about what this support actually means. Since a previous study [13] showed that organisational support (such as flexibility in work hours or situations) was important for remaining at work, we must now investigate what types of social support contribute most to positive work environments for individuals with disabilities. Different kinds of support will need different interventions.

Concerning the demographic data, the NW group was significantly older (50 years) than the $\mathrm{W}$ women in the present study. Still, the mean age and the duration of pain are similar to what has been reported in other studies[1,13]. However, the somewhat older age may be an explanation for individuals not being employed, as it was shown by both White et al [14] and Teasell and Finestone [15] that this was a factor associated with disability. In this study, $30 \%$ of the women were working outside the home, which is in reasonable agreement with other reports where work disability varies from $25 \%$ to $50 \%$ in patients with prolonged or chronic pain [5]. Sixty-nine percent of the NW women documented 
previous employment in occupations such as service, care, business, administration, customer service, and work without formal vocational training. However, only $48 \%$ of women in the Swedish workforce have reported these types of occupations [28]. Home care personnel, one of the largest female occupational groups in Sweden, is associated with working conditions that have been documented as unfavourable [29] due to physical as well as psychosocial factors. Daily tasks often include cleaning and lifting in awkward positions. The highest risks and most frequently reported cases of musculoskeletal accidents involve trained home help and health care workers [30]. The W women had a higher education than the NW women, which often leads to work situations that are easier to control and influence than those of less educated women. Being able to influence both the pace of work and when the tasks had to be done was reported by women in an interview study as a facilitating factor for remaining in a work role [13]. White et al [14] also showed that education level was a predictor for work capacity.

The NW group reported more severe disability and impact from pain than the W women. There was no difference between the $\mathrm{W}$ and NW women concerning duration of muscle pain, but the time since diagnosis differed significantly, with NW women having received their diagnoses much earlier. Pain-free periods were significantly lower in the NW group; this may show the complexity of pain and its consequences as described in the biopsychosocial model [19]. One suggestion is that those in the NW group were less successful in coping with their pain or were not able to distract from their pain at work. Despite pain, the NW women reported significantly higher severity than the W women concerning the following symptoms: stiffness, decreased muscle strength and endurance, 
pain or discomfort with sexual intercourse, abdominal pain/cramps, leg cramps, and concentration and memory difficulties. Except for pain or discomfort with sexual intercourse these are commonly described symptoms in previous studies concerning work and employability in persons with FM $[11,12,14]$. Only two of these symptoms, pain and stiffness, played a significant role in a multivariate context according to the PLS-DA model. In the model, the symptoms of headaches, feeling tense, numbness, difficulties with balance or dizziness, and painful chewing were important in discriminating the $\mathrm{W}$ from NW women.

In this study, the NW women had difficulty climbing stairs, doing shopping, visiting friends, doing the dishes, washing clothes, and doing yard work. Some of these activities are static and repetitive, and this may explain the difficulties with performing them. Many studies $[3,8,11,12]$ document that impairments present in persons with FM strongly influence their ability to manage daily activities and life roles, especially for non-working women [11].

To identify which variables discriminated the working women from the non-working, we used a multivariate projection method (PLS-DA), which is not widely used in healthrelated research. However, the advantages of PLS make the method very useful in healthrelated research. Advantages include the fact that PLS does not require interval scale data, is not sensitive to violations of multivariate normality, does not assume independence of cases, is not hampered by collinearity among variables and may be used with small sample sizes [31]. The data used in the present study are probably highly 
collinear, and since the FSI has had only limited psychometric testing, they needed to be analysed by a method that is robust when dealing with noisy data. When interpreting the results it is important to understand that no implication of causality is being made. The PLS-DA analysis describes the relationship between the independent variables and work status. Other analyses would be needed to examine questions of causality, such as whether a particular symptom is causing work disability or vice versa. That will demand a longitudinal design in future studies.

In the PLS-DA model, different factors appeared, besides symptoms and their impact on ability, that suggest an assessment of work capacity must include an assessment of the individual's total life situation. Factors that need to be taken into consideration include life context, other role commitments, work tasks, perceived control over work, and the physical and psychosocial work environment. This argument has been well stated by Bennet [16] and Bradley et al [17], who recommended that a well-performed assessment of disability should be based on a biopsychosocial model. It is notable that individuals with FM often experience better or worse periods where the pain intensity, pain localisation, and concomitant symptoms fluctuate over days and weeks [2].

To analyse the differences between the groups (W and NW), we chose to use parametric statistics. Since the multivariate PLS-DA analysis is based on a central mean scaling of data and therefore treats the data in a parametric way, this choice really needs to be discussed. To use parametric tests such as the Student's t-test, data should be continuous, the standard deviation in each group compared should be comparable, and observations 
in each group should be normally distributed [32]. Since the FSI is reported on an ordinal scale, the choice of parametric statistics can be challenged. To scrutinise the impact of using parametric statistics to identify differences in FSI and demographic data, the data were re-analysed using non-parametric statistics and no important differences were found.

\subsection{Limitations}

One limitation of the study is while all respondents stated that they had a fibromyalgia diagnosis, there was no way to determine whether they indeed met the diagnostic criteria at the time they completed the survey. The participants were not formally diagnosed. However, in the total project $(\mathrm{n}=362)$ only $13 \%$ did not answer the question about which health care professional had confirmed their diagnosis. All subjects described having pain for twelve years on average, and reported having received their diagnosis from a physician $(40 \%$ by a rheumatologist, $32 \%$ by a pain specialist, and $28 \%$ by a primary care physician). Further, the study is cross-sectional with the limitation that results are only confined to a specific point in time. Persons with FM are not a homogenous group. This may have influenced the results and should be taken into consideration as state of health and difficulties were only reported at the time of this cross-sectional study.

Further, it should be noted that data were collected via a self-reported questionnaire. It could have been useful to corroborate measures of disability level by using interviews. Further, by using interviews, additional data not included in pre-determined questionnaires may be obtained. Daltroy et al [33] suggest that self-reported data should 
be combined with standardised observed measures of function to avoid the bias arising from the fact that self-reported measures mean different things to different people.

To expand the time frame, the questionnaire included questions about past experiences, for example about social support from previous employers and colleagues amongst the non-working women. This information about previous employment may be affected by recall bias, as some of the women had stopped working a numbers of years ago. However, since previous research [13] including Swedish women showed that leaving work has been an event of great importance for women with FM, this factor is probably diminished. Since this was a study including only females from a specific part of Sweden, factors such as the health care system and social benefit systems may have influenced the results and may be emphasised when attempting generalisation.

\section{CONCLUSION}

In conclusion, the major finding is, in the context of the biopsychosocial model, that the social aspect (measured as social support) is of higher discriminating value than the bio aspect (measured as symptoms) even though non-working women report more severe symptoms. The non-working women reported lower social support from former colleagues and employers, which may further impact their chances of returning to work since support as a predictive factor for returning after a period of sick leave has been described in studies [26]. However, satisfaction and positive work experiences are known to be strong incentives for continuing [34]. This was also shown in an interview study [13] where a supportive climate with understanding workmates and supervisors was 
described as important for remaining in the work role. These results emphasise that adjustments are required not only at the individual level, but also at higher organisational levels. This is described by Jansson and Björklund [35] who emphasise that the back to work process should not be reduced to an individual problem, rather be regarded as an interactive problem with individual and structural environmental aspects. To change prevailing attitudes, behavioural responses and values towards persons with work disability, a process of active intervention, involving administrative and supervisory staff, is needed. Efforts need to focus on the education of employers in terms of how a disability may influence a work situation, and in what ways social support can be improved.

\section{ACKNOWLEDGMENTS}

The authors would like to thank Associate Professor L Eddy, and Professor C Burckhardt for their valuable comments on the manuscript. This study was supported financially by The Swedish Rheumatism Association. 


\section{REFERENCES}

[1] Wolfe F, Ross K, Anderson J, Russell IJ, Hebert L. The prevalence and characteristics of fibromyalgia in the general population. Arthritis Rheum 1995;38(1):19-28.

[2] Lindell L, Bergman S, Petersson IF, Jacobsson LT, Herrstrom P. Prevalence of fibromyalgia and chronic widespread pain. Scand J Prim Health Care 2000;18(3):149-53.

[3] Henriksson CM. Longterm effects of fibromyalgia on everyday life. A study of 56 patients. Scand J Rheumatol 1994;23(1):36-41.

[4] Kennedy M, Felson DT. A prospective long-term study of fibromyalgia syndrome. Arthritis Rheum 1996;39(4):682-5.

[5] Henriksson CM, Liedberg GM, Gerdle B. Women with fibromyalgia: work and rehabilitation. Disabil Rehabil 2005;27(12):685-94.

[6] Liedberg GM, Burckhardt CS, Henriksson CM. Validity and reliability testing of the Quality of Life Scale, Swedish version in women with fibromyalgia -- statistical analyses. Scand J Caring Sci 2005;19(1):64-70.

[7] Henriksson KG. Fibromyalgia--from syndrome to disease. Overview of pathogenetic mechanisms. J Rehabil Med 2003(41 Suppl):89-94.

[8] Henriksson C, Burckhardt C. Impact of fibromyalgia on everyday life: a study of women in the USA and Sweden. Disabil Rehabil 1996;18(5):241-8.

[9] Liedberg G, Hesselstrand M, Henriksson C. Time use and activity pattern in women with long term pain. Scand J Occup Ther 2004;11:1-10.

[10] Liedberg GM, Burckhardt CS, Henriksson CM. Young women with fibromyalgia in the United States and Sweden: perceived difficulties during the first year after diagnosis. Disabil Rehabil 2006;28(19):1177-84.

[11] Burckhardt C, Liedberg G, Kendall S, Henriksson C. The impact of fibromyalgia on work status of newly-diagnosed young women. J Musculoskel Pain 2005;13:31-41.

[12] Henriksson C, Liedberg G. Factors of importance for work disability in women with fibromyalgia. J Rheumatol 2000;27(5):1271-6.

[13] Liedberg GM, Henriksson CM. Factors of importance for work disability in women with fibromyalgia: an interview study. Arthritis Rheum 2002;47(3):266-74.

[14] White KP, Speechley M, Harth M, Ostbye T. Comparing self-reported function and work disability in 100 community cases of fibromyalgia syndrome versus controls in London, Ontario: the London Fibromyalgia Epidemiology Study. Arthritis Rheum 1999;42(1):76-83.

[15] Teasell RW, Finestone H. Socioeconomic factors and work disability: clues to managing chronic pain disorders. Pain Res Manage 1999:89-92.

[16] Bennett RM. Fibromyalgia and the disability dilemma. A new era in understanding a complex, multidimensional pain syndrome. Arthritis Rheum 1996;39(10):1627-34.

[17] Bradley L, Alarcon G, Alberts R. Pain in the workplace. New models of disability must focus on work rehabilitation. Pain Forum 1997(6):245-247.

[18] World Health Organization. International classification of functioning, disability and health (ICF). Geneva: World Health Organization; 2001.

[19] Engel GL. The need for a new medical model: a challenge for biomedicine. Science 1977;195:129-36.

[20] Burckhardt CS, Clark SR, Bennett RM. The fibromyalgia impact questionnaire: development and validation. J Rheumatol 1991;18(5):728-33. 
[21] Hedin PJ, Hamne M, Burckhardt CS, Engstrom-Laurent A. The Fibromyalgia Impact Questionnaire, a Swedish translation of a new tool for evaluation of the fibromyalgia patient. Scand J Rheumatol 1995;24(2):69-75.

[22] Eriksson L, Johansson E, Kettanen-Wold N, Wold S. Multi- and megavariate data analysis using the projection methods (PCA \& PLS). Umeå: Umetrics Academy; 2001. [23] Henningsson M, Sundbom E, Armelius BA, Erdberg P. PLS model building: a multivariate approach to personality test data. Scand J Psychol 2001;42(5):399-409. [24] ISCO. Gnesta: AMS Förlagsservice; 1996.

[25] Löfgren M, Ekholm J, Ohman A. 'A constant struggle': successful strategies of women in work despite fibromyalgia. Disabil Rehabil 2006;28(7):447-55.

[26] Janssen N, van den Heuvel WP, Beurskens AJ, Nijhuis FJ, Schroer CA, van Eijk JT. The Demand-Control-Support model as a predictor of return to work. Int J Rehabil Res 2003;26(1):1-9.

[27] House J. Work Stress and Social Support. Reading, MA: Addison-Wesley; 1981. [28] Statistiska centralbyrån [homepage on the internet]. Stockholm: SCB; 2009. [201112-10. 2011-12-10] Avalible from: http://www.scb.se/pages/product_23262.aspx [29] Gerdle B, Brulin C, Elert J, Granlund B. Factors interacting with perceived workrelated complaints in the musculoskeletal system among home care service personnel. An explorative multivariate study. Scand J Rehabil Med 1994;26(2):51-8.

[30] Statistiska centralbyrån. Sjukfrånvaro och ohälsa i Sverige - en belysning utifrån SCB:s statistik. Örebro; 2004. Report No.: 3.

[31] Pulos S, Rogness N. Soft modeling and special education. Remedial and special education 1995;16(3):184-192.

[32] Altman DG. Practical statistics for medical research. London: Chapman \& Hall; 2000.

[33] Daltroy LH, Larson MG, Eaton HM, Phillips CB, Liang MH. Discrepancies between self-reported and observed physical function in the elderly: the influence of response shift and other factors. Soc Sci Med 1999;48(11):1549-61.

[34] Karasek R, Theorell T. Psychosocial work environment. In: Healthy work: stress, productivity, and the reconstruction of working life. . New York: Basic books; 1990. p. 31-82.

[35] Jansson I, Bjorklund A. The experience of returning to work. Work 2007;28(2):12134. 
Table 1. Differences between working and non-working women with fibromyalgia.

\begin{tabular}{|c|c|c|c|}
\hline & $\begin{array}{r}\text { Working } \\
(\mathrm{n}=95)\end{array}$ & $\begin{array}{c}\text { Non-working } \\
(\mathrm{n}=227)\end{array}$ & \\
\hline Age, yrs, mean $\pm \mathrm{SD}$, (range) & $45.6 \pm 10.4(20-64)$ & $49.7 \pm 9.8(24-64)$ & .001 \\
\hline \multicolumn{4}{|l|}{ Family, n (\%) } \\
\hline Married/single/missing & $80(84) / 15(16) / 0(0)$ & $165(73) / 59(26) / 3(1)$ & .00 \\
\hline \multicolumn{4}{|l|}{ Children living at home } \\
\hline Yes/no/missing & $50(53) / 42(44) / 3(3)$ & $86(38) / 137(60) / 4(2)$ & .01 \\
\hline \multicolumn{3}{|l|}{ Education, $\mathrm{n}(\%)$} & \multirow[t]{5}{*}{.02} \\
\hline 9 years & $25(26)$ & $84(37)$ & \\
\hline 12 years & $49(52)$ & $116(51)$ & \\
\hline University & $20(21)$ & $20(9)$ & \\
\hline Others & $1(1)$ & $7(3)$ & \\
\hline Working, full-time/part-time, $\mathrm{n}(\%)$ & $12(13) / 83(87)$ & - & \\
\hline \multicolumn{3}{|l|}{ Level of Exercise $n(\%)$} & \multirow[t]{5}{*}{.005} \\
\hline Every day & $13(14)$ & $72(32)$ & \\
\hline 2-3 times/week & $37(41)$ & $76(34)$ & \\
\hline Once a week & $26(29)$ & $58(26)$ & \\
\hline Never & $14(16)$ & $17(8)$ & \\
\hline Muscle pain duration,, $\mathrm{yrs}$, mean $\pm \mathrm{SD}$, (range) & $12 \pm 7(0.9-34)$ & $12 \pm 8(0.8-45)$ & ns \\
\hline Time since diagnosis, yrs, mean $\pm \mathrm{SD}$, (range) & $5 \pm 4(4-20)$ & $7 \pm 5(0.3-32)$ & .01 \\
\hline \multicolumn{4}{|l|}{ Pain-free periods, $\mathrm{n}(\%)$} \\
\hline Yes & $25(26)$ & $58(25)$ & \multirow[t]{3}{*}{.04} \\
\hline No & $48(51)$ & $139(61)$ & \\
\hline Missing & $22(23)$ & $32(14)$ & \\
\hline \multicolumn{4}{|l|}{ Pain intensity, mean $\pm \mathrm{SD}$, (range) } \\
\hline Least & $2.7 \pm 1.9(0.1-9.4)$ & $3.5 \pm 2(0.0-10.0)$ & .01 \\
\hline At worst & $8 \pm 1.5(3.5-10.0)$ & $8 \pm 1.4(0.8-10.0)$ & ns \\
\hline Contact with physician last year mean $\pm \mathrm{SD}$ (range) & $1.7 \pm 0.7(1-4)$ & $1.7 \pm 0.7(1-4)$ & ns \\
\hline \multicolumn{4}{|l|}{ Social support from } \\
\hline Family, mean $\pm \mathrm{SD}$, (range) & $2.9 \pm 2.4(0.0-9.2)$ & $3.3 \pm 2.9(0.0-10.0)$ & ns \\
\hline Relatives, mean $\pm \mathrm{SD}$, (range) & $4.1 \pm 2.4(0.0-9.2)$ & $4.3 \pm 2.9(0.0-10.0)$ & ns \\
\hline Employer, mean $\pm \mathrm{SD}$, (range) & $4.5 \pm 3.0(0.0-9.8)$ & $6.9 \pm 3.1(0.0-10.0)$ & .00 \\
\hline Colleagues, mean $\pm \mathrm{SD}$, (range) & $3.6 \pm 2.9(0.0-9.8)$ & $6.5 \pm 3.1(0.0-10.0)$ & .00 \\
\hline \multicolumn{4}{|l|}{ Satisfaction with global life situation considering } \\
\hline \multicolumn{4}{|l|}{ Impact of symptoms on activities mean $\pm \mathrm{SD}$} \\
\hline Shopping & $1.4 \pm 0.8$ & $1.6 \pm 0.8$ & .02 \\
\hline Do laundry & $0.8 \pm 0.9$ & $1.0 \pm 0.9$ & .05 \\
\hline Prepare meals & $0.9 \pm 0.9$ & $1.1 \pm 0.8$ & .04 \\
\hline Dishes and cooking & $1.3 \pm 0.9$ & $1.5 \pm 0.9$ & ns \\
\hline Vacuum a rug & $1.9 \pm 1.0$ & $2.2 \pm 0.9$ & .01 \\
\hline Make beds & $1.4 \pm 0.9$ & $1.5 \pm 0.9$ & $\mathrm{~ns}$ \\
\hline Walk several blocks & $1.3 \pm 1.0$ & $1.6 \pm 1.0$ & .01 \\
\hline Visit friends or relatives & $1.4 \pm 1.0$ & $1.7 \pm 0.9$ & ns \\
\hline Do yard work & $2.1 \pm 1.0$ & $2.4 \pm 0.7$ & ns \\
\hline Drive a car & $0.9 \pm 0.8$ & $1.4 \pm 1.0$ & .00 \\
\hline
\end{tabular}


Table 2.Classification of occupation according to the Swedish version of the International Classification of Occupation (ISCO, 1996).

\begin{tabular}{lcc}
\hline Classification of Occupation & Working & $\begin{array}{c}\text { Non- } \\
\text { working } \\
\mathrm{n}(\%)\end{array}$ \\
\hline Management, leadership & $\mathrm{n}(\%)$ & $3(3)$ \\
Theoretical specialist competency (e.g. dentist, teacher) & $8(8.5)$ & $16(7)$ \\
Shorter academic education (e.g. preschool teacher, recreation leader) & $7(7.5)$ & $7(3.1)$ \\
Administration, customer service & $14(15)$ & $26(11.4)$ \\
Service, care, and business & $39(41)$ & $96(42.2)$ \\
Farming, gardening, fishing, forestry & $-(0)$ & $1(0.4)$ \\
Craftsmen, artisan, handicraft & $-(0)$ & $7(3.1)$ \\
Processing, machine operator, transport & $5(5)$ & $12(5.3)$ \\
Work without formal vocational training (e.g. cleaner, catering assistant) & $13(14)$ & $35(15.4)$ \\
Missing & $6(6)$ & $23(10.1)$ \\
Total & $95(100)$ & $227(100)$ \\
\hline
\end{tabular}

Table 3.Significant differences between working and non-working women in comorbidity

\begin{tabular}{llll}
\hline & $\begin{array}{l}\text { Working } \\
\mathrm{m} \pm \mathrm{SD}\end{array}$ & $\begin{array}{l}\text { Non-working } \\
\mathrm{m} \pm \text { SD }\end{array}$ & p-value \\
\hline Widespread pain or "hurting all over", & $3.2 \pm 0.9$ & $3.6 \pm 0.7$ & $\mathbf{. 0 0 0}$ \\
Fatigue or "tired all the time" & $3.6 \pm 0.7$ & $3.7 \pm 0.7$ & .332 \\
Stiffness & $3.2 \pm 0.8$ & $3.5 \pm 0.7$ & $\mathbf{. 0 0 2}$ \\
Decreased muscle strength & $3.2 \pm 0.9$ & $3.5 \pm 0.7$ & $\mathbf{. 0 1 1}$ \\
Decreased muscle endurance & $3.6 \pm 0.8$ & $3.8 \pm 0.6$ & $\mathbf{. 0 0 8}$ \\
Problems sleeping & $3.1 \pm 1.1$ & $3.3 \pm 1.1$ & .103 \\
Numbness or tingling sensations & $3.0 \pm 0.9$ & $3.1 \pm 1.0$ & .656 \\
Headaches & $2.9 \pm 1.2$ & $2.7 \pm 1.2$ & .307 \\
Swelling in hands, arms, legs or feet & $2.6 \pm 1.1$ & $2.8 \pm 1.2$ & .263 \\
Feeling tense, worried or "stressed out" & $3.0 \pm 1.2$ & $2.9 \pm 1.1$ & .513 \\
Feeling sad or blue & $2.3 \pm 1.1$ & $2.6 \pm 1.2$ & .084 \\
Problems with menstrual periods or "PMS" & $1.7 \pm 1.6$ & $1.7 \pm 1.7$ & .927 \\
Pain or discomfort with sexual intercourse & $1.5 \pm 1.3$ & $1.9 \pm 1.4$ & $\mathbf{. 0 1 1}$ \\
Low sex drive/decreased libido & $2.5 \pm 1.4$ & $2.7 \pm 1.4$ & .266 \\
Problems with urination-pain, urgency, or & $1.3 \pm 1.3$ & $1.6 \pm 1.5$ & .070 \\
frequency & & & \\
Dry mouth & $2.0 \pm 1.4$ & $2.4 \pm 1.4$ & $\mathbf{. 0 3 9}$ \\
Dry or scratchy eyes & $2.2 \pm 1.3$ & $2.3 \pm 1.4$ & .516 \\
Irritable bowels: constipation & $2.0 \pm 1.5$ & $2.2 \pm 1.4$ & .408 \\
Irritable bowels: diarrhoea & $1.4 \pm 1.4$ & $1.7 \pm 1.5$ & .057 \\
Abdominal pain/cramps & $1.7 \pm 1.3$ & $2.1 \pm 1.5$ & $\mathbf{. 0 2 5}$ \\
Restless legs or leg cramps & $2.5 \pm 1.2$ & $2.8 \pm 1.2$ & $\mathbf{. 0 2 5}$ \\
Leg cramps during night & $1.7 \pm 1.4$ & $1.9 \pm 1.5$ & $\mathbf{. 0 3 6}$ \\
Problems with concentration & $3.0 \pm 1.1$ & $3.3 \pm 1.0$ & $\mathbf{. 0 1 4}$ \\
Problems with memory & $2.8 \pm 1.1$ & $3.2 \pm 1.0$ &. $\mathbf{0 0 5}$ \\
Difficulty with balance or dizziness & $2.3 \pm 1.2$ & $2.5 \pm 1.2$ & .213 \\
Sinus pain, congestion or stuffiness & $1.5 \pm 1.4$ & $1.7 \pm 1.4$ & .274 \\
Painful chewing or "TMJ" & $1.8 \pm 1.4$ & $1.9 \pm 1.4$ & .499 \\
Cold sensitivity in hands or feet & $3.0 \pm 1.3$ & $3.2 \pm 1.3$ & .209 \\
Tenderness for touch & $3.6 \pm 0.9$ & $3.7 \pm 0.9$ & .441 \\
\hline
\end{tabular}


Table 4. The important variables in discriminating between $\mathrm{W}$ and NW. Variables with VIP-value $>1.0$ were defined as significant predictors.

\begin{tabular}{|c|c|c|}
\hline No & Variable & VIP-value \\
\hline 1 & Support from colleagues & $2.9+$ \\
\hline 2 & Support from employer & $2.4+$ \\
\hline 3 & Ability to drive a car & $1.7+$ \\
\hline 4 & Age & $1.6-$ \\
\hline 5 & Exercise every day & $1.5+$ \\
\hline 6 & Headaches & $1.5-$ \\
\hline 7 & Least pain intensity & $1.3+$ \\
\hline 8 & Time since diagnosis & $1.3+$ \\
\hline 9 & Climbing stairs & $1.2+$ \\
\hline 10 & Children living at home & $1.2+$ \\
\hline 11 & Higher education & $1.2+$ \\
\hline 12 & Non-regular exercise & $1.2-$ \\
\hline 13 & $\begin{array}{l}\text { Feeling tense, worried or "stressed } \\
\text { out" }\end{array}$ & $1.1-$ \\
\hline 14 & Numbness or tingling sensations & $1.1-$ \\
\hline 15 & Doing shopping & $1.1+$ \\
\hline 16 & $\begin{array}{l}\text { Difficulty with balance or } \\
\text { dizziness } \\
\text { Doing laundry with a washer and }\end{array}$ & $1.1-$ \\
\hline 17 & dryer & $1.1-$ \\
\hline 18 & Pain intensity at worst & $1.1-$ \\
\hline 19 & Painful chewing or TMJ & $1.1-$ \\
\hline 20 & Doing yard work & $1.0+$ \\
\hline 21 & Stiffness & $1.0+$ \\
\hline 22 & $\begin{array}{l}\text { Vacuuming a rug } \\
\text { Washing dishes/cooking utensils }\end{array}$ & $1.0+$ \\
\hline 23 & by hand & $1.0+$ \\
\hline 24 & Visiting friends or relatives & $1.0+$ \\
\hline
\end{tabular}

+ indicates a positive relation to working and

- indicates a negative relation. 